STR\|PPED BARE

THE ART OF

$\mathbb{A} \mathbb{N} \| \mathbb{A} L \mathbb{A} \mathbb{N} \mathbb{A} T O M \mathbb{Y}$

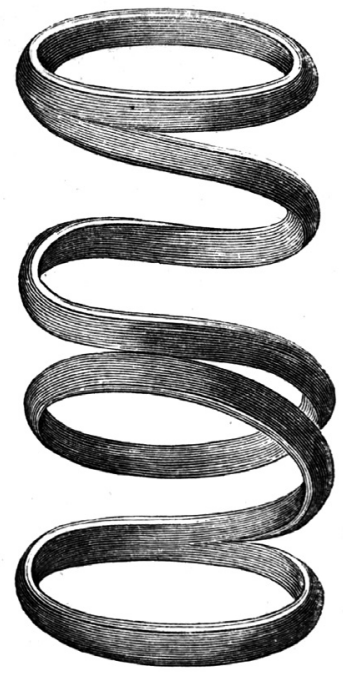

$\mathbb{D} \mathbb{A} \vee \mathbb{D} B \mathbb{A}\|\mathbb{N} \mathbb{R}\| \mathbb{D} G E$ 


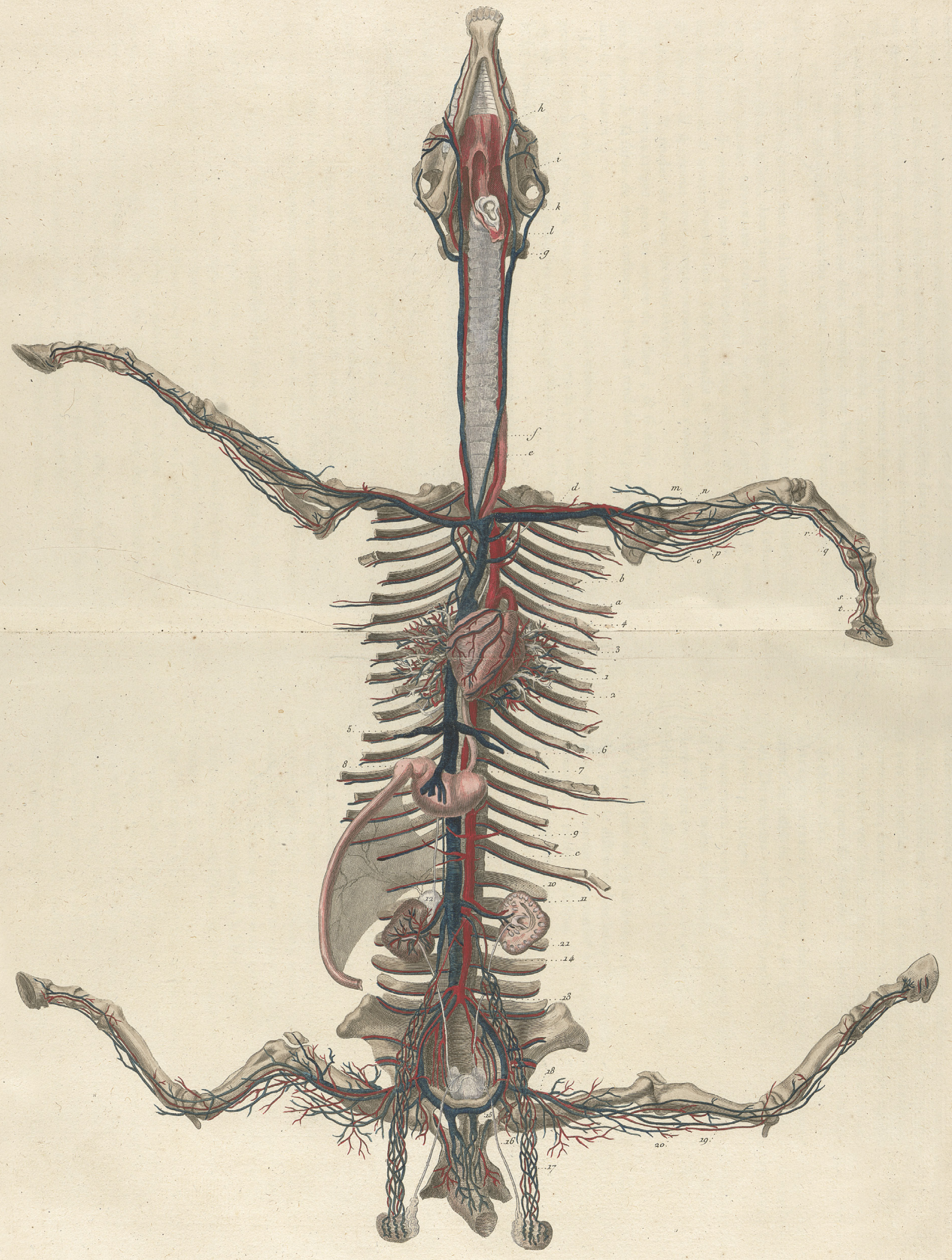




\section{STR\|PPED BARE}

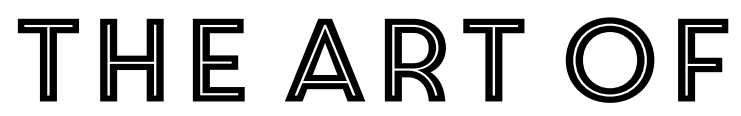

$\mathbb{A} \mathbb{N} \| \mathbb{A} L \mathbb{A} \mathbb{N} A T O M Y$

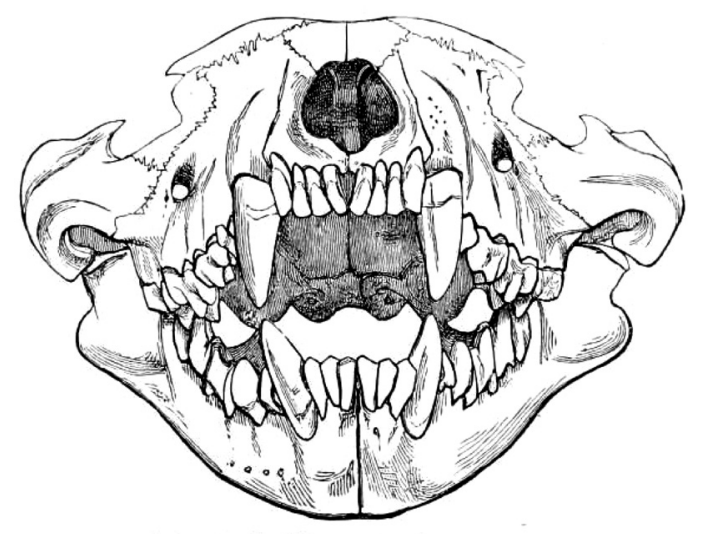

$\mathbb{D} \mathbb{A}\|\mathbb{B} \mathbb{B}\| \mathbb{N} \mathbb{B} \| \mathbb{D} \mathbb{E}$

$P R\|\mathbb{N} C E T O N \cup \mathbb{N}\| V E R S \| T Y P R E S S$

$P \mathbb{R} \| \mathbb{N} C T O \mathbb{N} \mathbb{N} D O X F O R D$ 
To Michael Blooman,

For the art, Italy, and new ways of seeing.

Published in 2018 by Princeton University Press 41 William Street

Princeton, New Jersey 08540

press.princeton.edu

() 2018 Quarto Publishing plc an imprint of The Quarto Group

All rights reserved. No part of this publication may be reproduced or transmitted in any form or by any means, electronic or mechanical, including photocopy, recording or any information storage and retrieval system, without prior permission in writing from the publisher.

Library of Congress Control Number: 2018935458

ISBN 978-0-691-18142-4

\section{QUAR.SKEL}

Conceived, edited, and designed by Quarto Publishing plc, an imprint of The Quarto Group

Design: Blok Graphic, London

Editor: Kate Burkett

Art editor: Jackie Palmer

Picture researcher: Sara Ayad

Publisher: Samantha Warrington

Printed in China

10987654321

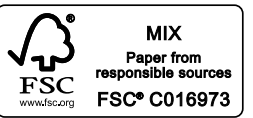

